\title{
BMJ Open What matters most and for whom? A cross-sectional study exploring goals of health professionals in German neonatal intensive care units
}

\author{
Anne Mensen (D) , ,,2 Bernhard Roth,, ${ }^{3,4}$ Ludwig Kuntz, ${ }^{4}$ Michael Wittland, ${ }^{5}$ \\ Verena Glöckner, ${ }^{4}$ Felix Miedaner ${ }^{6}$
}

To cite: Mensen A, Roth B, Kuntz L, et al. What matters most and for whom? A crosssectional study exploring goals of health professionals in German neonatal intensive care units. BMJ Open 2021;11:e044031. doi:10.1136/ bmjopen-2020-044031

- Prepublication history and supplemental material for this paper is available online. To view these files, please visit the journal online (http://dx.doi org/10.1136/bmjopen-2020044031).

Received 20 August 2020 Revised 08 February 2021 Accepted 26 February 2021

Check for updates

(C) Author(s) (or their employer(s)) 2021. Re-use permitted under CC BY-NC. No commercial re-use. See rights and permissions. Published by BMJ.

For numbered affiliations see end of article.

Correspondence to

Ms Anne Mensen;

anne.mensen@rwi-essen.de

\section{ABSTRACT}

Objectives Quality of care largely depends on successful teamwork, which in turn needs effective communication between health professionals. To communicate successfully in a team, health professionals need to strive for the same goals. However, it has been left largely unaddressed which goals professionals consider to be important. In this study, we aim to identify these goals and analyse whether differences between (1) personal and organisational goals, (2) different professions and (3) hierarchical levels exist in neonatal intensive care units (NICUs).

Design Goals were identified based on a literature review and a workshop with health professionals and tested in a pilot study. Subsequently, in the main study, a crosssectional employee survey was undertaken.

Setting and participants 1489 nurses and 537 physicians from 66 German NICUs completed the questionnaire regarding personal and organisational goal importance between May and July 2013. Answers were given based on a 7-point Likert scale varying between none and exceptionally high importance.

Results Results show that the goals can be subdivided into three main goal dimensions: patients, parents and staff. Furthermore, our results reveal significant differences between different professions and different hierarchical level: physicians rated patient goals with a mean $(95 \% \mathrm{Cl})$ importance of 6.37 (6.32 to 6.43$)$, which is significantly higher than nurses with a mean $(95 \% \mathrm{Cl})$ importance of 6.15 (6.12 to 6.19) $(p<0.01)$. Otherwise, nurses classified parental goals as more important $(p<0.01)$. Furthermore, professionals in leading positions rate patient goals significantly higher than professionals that are not in leading positions (6.36 (6.28 to 6.44$)$ vs 6.19 (6.15 to 6.22), $p<0.01$ ).

Conclusions Different employee goals need to be considered in decision-making processes to enhance employee motivation and the effectiveness of teamwork. Trial registration number DRKS00004589.

\section{INTRODUCTION}

Effective teamwork plays an essential role for health professionals, as it is supposed to reduce medical error rates and enhance patient outcomes. ${ }^{1-3}$ Some of the most
Strengths and limitations of this study

- Our study includes a broad setting of 66 German neonatal intensive care units and more than 2000 physicians and nurses working in the respective hospital units.

- By exploring the differences of professionals' goals in the neonatal setting, this study helps to better understand their individual needs to foster motivation and successful teamwork.

- Our study explores different goals in the neonatal setting. Associations to teamwork or motivation were not examined but bear a fruitful direction to future research.

frequent contributory factors for medical errors in neonatal intensive care units (NICUs) are communication problems and poor teamwork. ${ }^{4}$ In a review, Dietz et $a \tilde{l}$ generate a framework of intensive care unit team performance that identifies goal clarification as one key factor for the effectiveness of team processes. Previous studies already demonstrate that patient goal sheets can successfully improve communication between health professionals, ${ }^{67}$ but to our knowledge, no study so far has pointed out in detail which goals are considered important by physicians and nurses and the extent to which their assessment differs.

Before describing our analytical framework, we first explain the theoretical background including how goals influence an individual's behaviour and why we expect differences between different professions and by hierarchical level. Drawing on goal-setting theory, ${ }^{8}$ goals describe the intention behind individual or organisational behaviour. Four mechanisms explain how goals influence performance: first, goals direct attention to goal-relevant activities both cognitively and behaviourally; second, they stimulate people 
to put effort into achieving these goals; third, they ensure persistence and encourage individuals to continue in their endeavours to reach their goals; finally, goals have an indirect effect on behaviour as they guide the focus in the use and creation of task-relevant knowledge and strategies. ${ }^{9-11}$

Physicians and nurses are strongly motivated by social and professional values grounded in their profession. ${ }^{12}$ A professional is characterised by deeply ingrained attitudes and behaviours accumulated over years of training and by membership in a professional group, resulting in strong ties to this group. ${ }^{13}$ The importance professionals put on goals in daily work is therefore strongly related to their profession. Furthermore, it is of great importance whether the organisation a professional works for pursues the same goals as he or she.

In general, hospitals can be characterised as professional organisations that strive for achieving similar goals to those of their members, ${ }^{14}$ turning them into favourable places for professionals to work. ${ }^{15}$ Consequently, differences between personal and perceived organisational goals may veer professionals away from their organisations, resulting in lower motivation and well-being during work and in decreased intent to stay.

A clear understanding of what is considered important by healthcare professionals is thus crucial to enhance employee motivation and the effectiveness of teamwork. However, professionals' personal and organisational goals in neonatal care have been left largely unaddressed. Therefore, the purpose of our study is to explore what healthcare professionals believe to be important for themselves and for their organisation (personal and perceived organisational goals). In doing so, we differentiate between both employee's profession (physicians vs nurses) and hierarchical level (individuals holding a position with vs without managerial responsibilities). We refer to the setting of neonatal intensive care, where health professionals and patients and patients' parents are actively involved in the treatment process. Thus, due to different aspirations, numerous goals must be considered.

\section{METHODS}

Step 1: identification of relevant personal and organisational goals in NICUs

First, we conducted a workshop with 10 nurses and 10 physicians working at the NICU of the University Hospital of Cologne, who were asked about their most important goals within a NICU. As the workshop included only staff members, an approval by the ethics commission was not necessary. However, the workshop was approved by the responsible staff council and data protection officer of the hospital where the workshop was carried out. Making use of the Nominal Group Technique, ${ }^{16}$ we ensured that each participant wrote down his or her own ideas about important goals in NICUs anonymously on index cards. Thus, possible distractions or unequal participation in the idea generation process of the participants were minimised. ${ }^{17}$ Afterwards, all ideas were collected, read aloud and summarised in a joint discussion of all workshop participants. Second, we identified potentially important goals within neonatal care based on overall objectives of an organisation according to Thommen. ${ }^{18}$ Finally, 15 personal as well as organisational goals were identified based on the workshop and a literature review and were included in the survey only if they were present in both, the workshop and the literature review. The goals were validated in a pretest with several non-project participants regarding understandability, clearness and completeness. Furthermore, the goals were validated in an employee survey addressing 198 nurses and 70 physicians of five participating NICUs in a pilot study to assess content validity. Principal component analysis revealed three components, which were determined using KaiserGuttman criterion, ${ }^{19}$ reflecting dimensions of patient, parental and staff goals. All items were retained due to sufficient factor loadings and showed good to excellent reliability according to Cronbach's alpha (detailed analyses of psychometric properties were shown elsewhere ${ }^{20}$; the questionnaire is shown in online supplemental appendix figure A1).

\section{Step 2: main study}

The final 15-item questionnaire on personal and perceived organisational goal importance was included in an employee survey that was sent to 66 German NICUs as part of the Health Services Research in Neonatal Intensive Care Units (HSR-NICU) study. The study is registered in the German Clinical Trials.

The nurses and physicians working in the participating NICUs were informed about the HSR-NICU study and the included employee survey via a study brochure. Afterwards, the questionnaires were sent to the participating NICUs in May 2013, where they were located at a suitable location so that all nurses and physicians from the respective NICU had the possibility to participate but were not obliged to take part. The questionnaires were anonymously returned in locked boxes after 3 months.

Each goal was rated twice: in the first place, according to the personal importance ('What importance do you attribute to this goal?') and, in the second place, according to the perceived hospital units, that is, organisational importance ('What importance does your ward attribute to this goal?'). Answers were given based on a 7-point Likert scale that varies between 'none' and 'exceptionally high' (see online supplemental appendix figure A1).

\section{Analysis}

To begin with, we analysed general differences between personal and perceived organisational goals. Subsequently, we examined differences in the importance of goals between occupational groups (physicians vs nurses) and between hierarchical levels (individuals holding a position with vs without managerial responsibilities). Classified as 'having managerial responsibility' are, in case of 
physicians, all head and senior physicians and, in case of nurses, all nurses with leadership duties.

We used analysis of variance and, if the assumption of homogenous variances was violated, Mann-Whitney U test to examine differences in the goal importance rating between different professions and across hierarchical groups. The paired sample t-test was used to consider differences between personal and perceived organisational goals within the same goal dimension. Statistical analyses were performed using Stata V.14 (College Station, Texas, USA).

\section{Patient and public involvement}

Patients and/or the public were not involved in the design, or conduct, or reporting, or dissemination plans of this research.

\section{RESULTS}

\section{Data and setting}

We asked all existing German NICUs $(n=229)$ to take part in the survey, where 66 NICUs $(29 \%)$ agreed to take part. According to selected characteristics at NICU- and hospital level, the participating NICUs were not significantly different from NICUs who did not take part in the study (for more information regarding the representativeness of the study sample, we refer to refs 21-23). A total of 3045 employees from the participating NICUs had the possibility to take part. A total of 2059 of them completed the questionnaire, which results in an average response rate of $67.6 \%$. The participants included 1489 nurses (72\%) and 537 physicians (26\%). Thirty-three (2\%) participants did not report their profession and were thus not included in the analysis. Characteristics of healthcare professionals are shown in table 1.

\section{Dimensional structure of goal items, validity and reliability}

Following the pilot study, we determined the dimensional structure for the goal items using confirmatory factor analysis (CFA) and estimated reliability using Cronbach's $\alpha{ }^{24}$ Results of the CFA reaffirmed the findings of the pilot study, indicating that the 15-item questionnaire (for both personal and perceived organisational goals) appears to be three-dimensional, reflecting dimensions of patient, parental and staff goals. Consequently, the items were subsequently broken down into separate goal domains related to patients, parents and staff.

After CFA analysis, the questionnaire about personal and perceived organisational goals showed an insufficient overall model fit according to the $\chi^{2}$ statistics $\left(\chi^{2}(87)=1248, p<0.001\right.$ for personal goals; $\chi^{2}(87)=1347$, $\mathrm{p}<0.001$ for organisational goals). However, these might be caused and inflated by the large sample size or the departures from multivariate normality. ${ }^{25}$ Indices of absolute and incremental goodness of fit that are robust to sample size showed acceptable values of fit (Personal goals: root mean square error of approximation $($ RMSEA) $=0.08$,
Table 1 Characteristics of participating health professionals

\begin{tabular}{|c|c|c|}
\hline Health professionals & $\begin{array}{l}\text { Nurses } \\
(n=1489)^{*}\end{array}$ & $\begin{array}{l}\text { Physicians } \\
(n=537)^{\star}\end{array}$ \\
\hline \multicolumn{3}{|l|}{ Gender, n (\%) } \\
\hline Female & $1392(98.0)$ & $311(59.2)$ \\
\hline Male & $29(2.0)$ & $214(40.8)$ \\
\hline \multicolumn{3}{|l|}{ Age class, $n(\%)$} \\
\hline$\leq 30$ & $390(26.9)$ & $137(25.9)$ \\
\hline $31-40$ & $385(26.6)$ & $247(46.7)$ \\
\hline $41-50$ & $492(33.9)$ & $96(18.2)$ \\
\hline $51-60$ & $170(11.7)$ & $45(8.5)$ \\
\hline$\geq 61$ & $13(0.9)$ & $4(0.8)$ \\
\hline \multicolumn{3}{|c|}{ Work experience in years, mean (SD) } \\
\hline In hospitals & $18.9(10.7)$ & $10(8.1)$ \\
\hline In NICUs & $15.2(10.0)$ & $7.3(7.5)$ \\
\hline \multicolumn{3}{|c|}{ Managerial responsibility, n (\%) } \\
\hline In leading position & $104(7.0)$ & $160(29.8)$ \\
\hline Without leading position & $1385(93.0)$ & 377 (70.2) \\
\hline
\end{tabular}

*Some variables do not sum up to the total number of observations due to missing information in those variables.

( standardised root mean square residual $(\mathrm{SRMR})=0.06$, Comparative Fit Index (CFI) $=0.94$, Tucker-Lewis index $(\mathrm{TLI})=0.92$; organisational goals: RMSEA $=0.09$, SRMR $=0.06, \mathrm{CFI}=0.94$ and $\mathrm{TLI}=0.93$ ) according to $\mathrm{Hu}$ and Bentler. ${ }^{26}$ Factor loadings of all items were significant, and all goal domains showed good to excellent reliability according to Cronbach's $\alpha$ coefficients (personal goals: $\alpha$ (patients $)=0.84, \alpha$ (parents $)=0.92, \alpha($ staff $)=0.80$; organisational goals: $\alpha($ patients $)=0.86, \alpha($ parents $)=0.94$, $\alpha($ staff $)=0.87)$.

\section{Descriptive results}

The average importance rating for each of the 15 goals is shown in figure 1. Generally, none of the goals were considered to be of none or very low importance. In contrast, most of the personal goals were rated at least with high importance.

Nonetheless, the importance rating obviously changes between the three goal dimensions as table 2 verifies. The first dimension patient is ranked with a mean $(95 \% \mathrm{CI})$ importance of 6.21 (6.18 to 6.24), whereas the second dimension parents is ranked slightly lower with an average importance of 5.93 (5.90 to 5.97). Lastly, staff-related goals are ranked the least important with a mean value of 5.18 (5.14 to 5.22 ).

In the following, we describe the main differences between: (1) personal and perceived organisational goals, (2) physicians and nurses and (3) different hierarchical levels. 


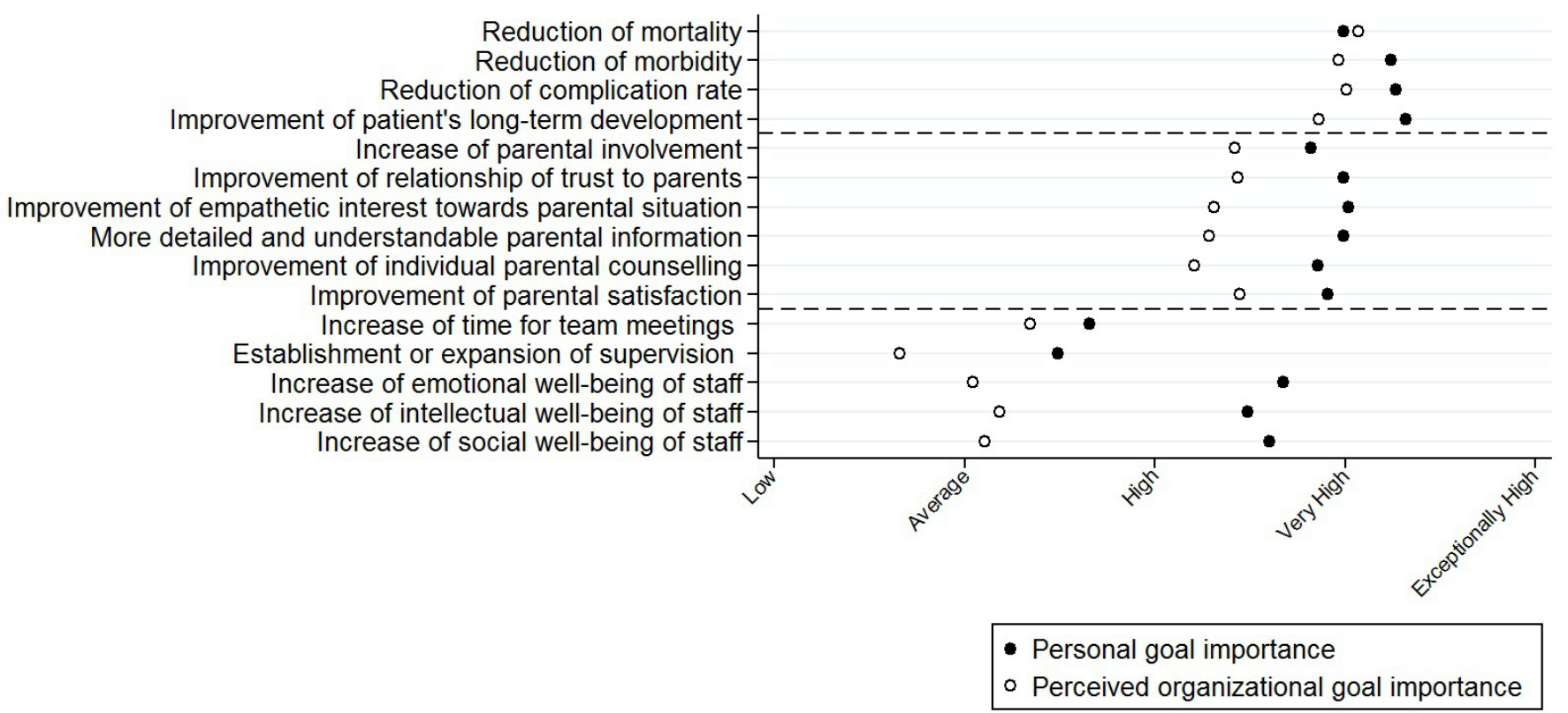

Figure 1 Personal and perceived organisational goals. Please note that the dashed lines show the three goal dimensions (patient goals: reduction of mortality, reduction of morbidity, reduction of complication rate and improvement of patient's long-term development; parental goals: increase of parental involvement, improvement of relationship of trust to parents, improvement of empathetic interest towards parental situation, more detailed and understandable parental information and improvement of parental satisfaction; staff goals: increase of time for team meetings, establishment or expansion of supervision, increase of emotional well-being of staff, increase of intellectual well-being of staff and increase of social well-being of staff).

\section{Differences between personal and perceived organisational goals}

Healthcare professionals rated the goals significantly different for themselves and their hospital unit. Overall, the perceived organisational goal importance of a healthcare professional is much lower compared with his or her personal goal rating. This is particularly noticeable for parental goals (mean (95\% CI) value of 5.93 (5.90 to 5.97) for personal versus 5.35 (5.31 to 5.40) for perceived organisational goals, $\mathrm{p}<0.01)$ as well as for staff goals (mean $(95 \% \mathrm{CI}$ ) value of 5.18 (5.14 to 5.22$)$ for personal versus 4.06 (4.01 to 4.12) for perceived organisational goals, $\mathrm{p}<0.01)$. For patient goals, there was only a small deviation between the perceived organisational goal importance and healthcare professionals' personal goal rating (mean $(95 \% \mathrm{CI}$ ) value of 6.21 (6.18 to 6.24$)$ for personal versus 5.98 (5.94 to 6.02) for perceived organisational goals, $\mathrm{p}<0.01$ ), meaning that patients goals are of exceptionally high importance for health professionals and, similarly, they believe their hospital unit puts a high emphasis on these goals.

\section{Differences between physicians and nurses}

The results in table 2 highlight that physicians and nurses rated the goals significantly different. Considering personal goals, physicians classified patient goals as significantly more important than nurses (mean (95\% CI) value of 6.37 (6.32 to 6.43 ) vs 6.15 (6.12 to 6.19$), \mathrm{p}<0.01$ ),

Table 2 Comparison of goal importance rating categorised by profession*

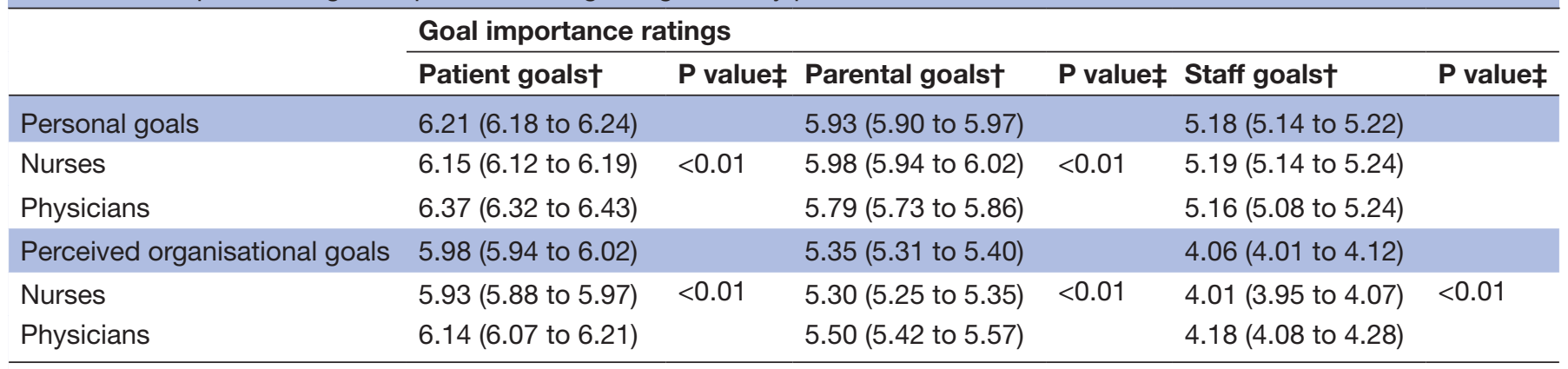

${ }^{*}$ Response based on 7-point Likert scale with 1 =none, $2=$ very low, $3=$ low, 4=average, $5=$ high, $6=$ very high, $7=$ exceptionally high . †Mean, $95 \% \mathrm{Cl}$ are shown in parentheses.

$\ddagger$ Using analysis of variance and, in case of heterogeneous variances, Mann-Whitney $U$ test. 
Table 3 Comparison of goal importance rating categorised by profession and managerial position*

\section{Goal importance ratings}

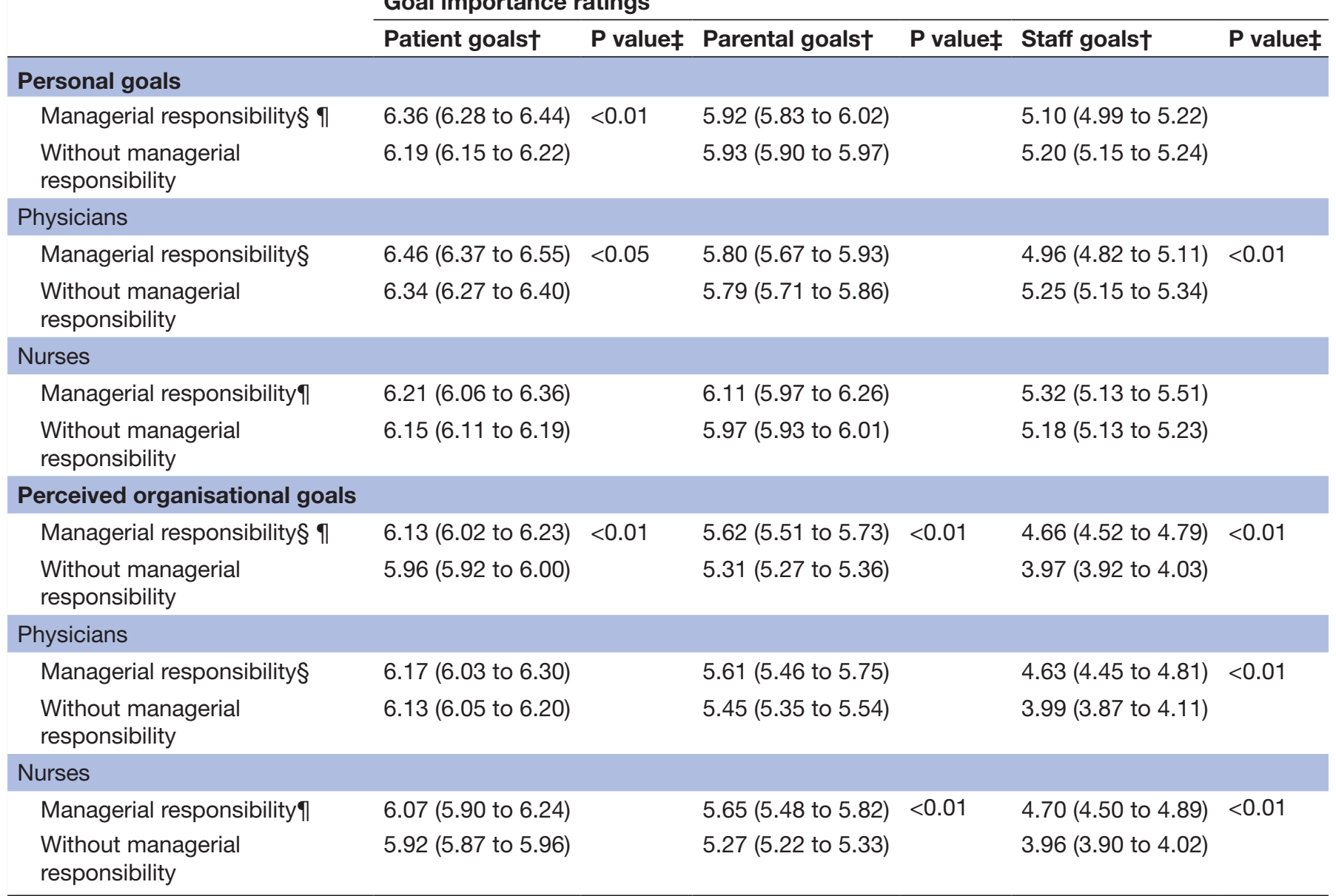

${ }^{*}$ Response based on 7-point Likert scale with 1=none, 2=very low, 3=low, 4=average, 5=high, 6=very high and 7=exceptionally high. †Mean, SD are shown in parentheses.

fUsing analysis of variance and, in case of heterogeneous variances, Mann-Whitney $U$ test.

§Referring to head and senior physicians.

१Referring to nurses with leadership duties.

whereas physicians rated the importance of parental goals significantly lower (mean $(95 \% \mathrm{CI})$ value of 5.79 (5.73 to $5.86)$ vs 5.98 (5.94 to 6.02$), \mathrm{p}<0.01)$. Only staff-related goals are rated similar by nurses and physicians with an average $(95 \% \mathrm{CI})$ value of 5.19 (5.14 to 5.24$)$ versus 5.16 (5.08 to 5.24). With regard to the perceived organisational importance, nurses rated all three goal categories significantly lower than physicians $(\mathrm{p}<0.01)$.

Differences between employees at different hierarchical levels Healthcare professionals of different hierarchical levels evaluated the goals significantly different. Head and senior physicians classified patient goals as significantly more important than physicians without managerial responsibility (mean $(95 \% \mathrm{CI}$ ) value of 6.46 (6.37 to 6.55$)$ vs 6.34 (6.27 to 6.40$)), \mathrm{p}<0.05)$. In contrast, staff goals were rated significantly lower by physicians with managerial responsibility (mean $(95 \% \mathrm{CI})$ value of 4.96 (4.82 to 5.11 ) vs 5.25 (5.15 to 5.34$), \mathrm{p}<0.01)$. The respective results are shown in table 3 .
In addition, healthcare professionals with managerial responsibility perceive their organisational unit to attribute a higher importance to the considered goals, whereas professionals without managerial responsibility perceive their units to attribute a much lower importance. This is especially remarkable for the last goal dimension staff (mean (95\% CI) value of 4.63 (4.45 to 4.81$)$ vs 3.99 (3.87 to 4.11), $\mathrm{p}<0.01$ ). Furthermore, nurses who are not in a leading position perceive a significantly lower organisational goal importance with respect to parental goals than nurses in leading positions (mean (95\% CI) value of 5.27 (5.22 to 5.33 ) vs 5.65 (5.48 to 5.82 ), $\mathrm{p}<0.01$ ).

\section{DISCUSSION}

High-risk patients require well-coordinated team members as even small discrepancies in the professionals' collaborative work can have serious consequences. The hierarchical structure in healthcare makes communication openness and speaking up even more important 
for patient safety. ${ }^{27}$ Healthcare professionals who aim for differing goals in their daily work may have larger problems to work together successfully. Thus, we argue that employee goals, as important motivational constructs, must be included in the ongoing debate of how to improve teamwork. This study identifies that differences in prioritisation of goals are salient between healthcare professionals of different professions and at different hierarchical levels.

Numerous procedures, such as team trainings or goal sheets, are designed to improve teamwork in the intensive care setting. Previous studies, which focused on nursephysician collaboration, referred to general differences in the behavioural patterns of physicians and nurses in their daily work. For instance, Senot $e t a l^{28}$ emphasises the physicians' tendency to focus primarily on the patient's disease, whereas nurses are more focused on the patient's overall well-being. When addressing differences in perceptions, previous research in neonatal care focused mainly on differences between professionals and parents, ${ }^{29}$ but no study has so far explored differences in perceptions among healthcare professionals. To our knowledge, this is the first study pointing out in detail what is considered important by physicians and nurses in NICUs and the degree to which their assessment is comparable.

Looking at our results at first glance, nearly all goals show a relatively high importance rating on the personal as well as on the perceived organisational level, indicating the character of hospitals as professional organisations. ${ }^{1415}$ As most of the participating employees put high importance on the considered goals, the workforce in the studied NICUs can be described as highly motivated, indicating a good basis for high-quality outcomes. ${ }^{8}$

Nevertheless, the analyses come up with important differences between different groups. First, the identified differences between personal and perceived organisational goal importance might be of great interest regarding the employees' identification with their organisations. Perceived organisational goals are rated significantly lower by nurses compared with physicians with respect to all three goal dimensions, revealing that nurses, in comparison with physicians, believe their hospital unit to be less concerned about patient, parental and staff goals.

Second, the analysis reveals that physicians classify patient goals as more important than nurses, whereas they assess parental goals on average as less important than nurses. On the one hand, one can argue that these differences between physicians and nurses are associated with decreased team performance, assuming that it matters whether individuals in a group agree on goals or not. Goal conflict has been identified as motivating competing individual actions and reducing performance ${ }^{30}$ whereas goal alignment reveals performance benefits. ${ }^{31}$ Referring to the framework of ICU team performance by Dietz et $a \tilde{e}$ professionals' goals can impact patient outcomes indirectly via its impact on the effectiveness of teamwork. Taking this thought further, the identified differences in prioritisation of goals may explain existing difficulties in collaboration between nurses and physicians, which underpins the relevance of regular interactions between hospital staff members. Furthermore, it may explain why patient goal sheets can improve communication and teamwork ${ }^{7}$ as these may harmonise goals on an operational level. However, different prioritisation of goals may also arise due to a clear division of labour between physicians and nurses. Potentially, physicians focus more intensively on their patients while spending less time with the newborn's parents. Conversely, nurses spend more time with the parents and may thus rate the importance of parental goals as more important than physicians. Previous studies showed that nurses indeed have more direct contact with parents. ${ }^{32}{ }^{33}$ In addition, Franck and Axelin ${ }^{34}$ showed that physicians seem to be aware of their time-limited parental support: on a scale ranging from 1 to 5, physicians rate their provided parental support with an average of 3.85 indicating that they provide support 'some or most of the time'. On the contrary, nurses evaluated their parental support at a mean score of 4.43. If these differences are the results of an effective division of labour, they may evoke synergies and could help to address the different needs and aspirations of both, patient as well as parents during the treatment process. It should be elaborated in further research whether different goals hamper teamwork or whether they reflect a well-functioning team.

Third, healthcare professionals without managerial responsibility perceive their hospital unit to be less concerned about the goals than their departmental leaders. This is shown for all goal dimensions, namely patients, parents and staff. Thus, organisations seem to be able to communicate and agree on common goals with their departmental leaders but show shortcomings in communicating these goals to their employees. As argued, this is especially important in hospitals to ensure adequate working conditions for professionals. Hence, improving the awareness of caregivers, which are not in leading positions, about how important these goals are for their hospital unit may increase employee motivation.

Moreover, these differences are especially important in the staff dimension, implying that employees believe their organisations do not place as high emphasis on the well-being and conditions in their working environment as they do. Especially in light of the increasing shortage of nurses and physicians, ${ }^{35} 36$ organisations should address these issues and thereby increase attractiveness for employees. Adequate staffing levels reached by making employment attractive and by having motivated staff in turn may result in better quality.

\section{Limitations}

Our study provides important insights on both personal and perceived organisational goals based on a comprehensive data source that includes multiple NICUs. Nevertheless, this research has some limitations, and its results should be interpreted in light of these. First, there can 
be a potential discrepancy between healthcare professionals' goals and their actual behaviour. Second, we did not examine the extent to which the identified differences impact the effectiveness of teamwork or patient outcomes. However, analysing this link goes beyond the scope of our study, which serves as a first step to a deeper understanding of human processes of team coordination that may enable us to better understand the relationship between team behaviour and patient outcomes. Third, since we analyse goal importance in the NICU setting, where parents have an extraordinary role, it would have been interesting to include the parental view on different goals. Unfortunately, we only interviewed physicians and nurses regarding their goal importance. Analysing parental goals and their agreement with staff goals might bear a fruitful direction for further research. Finally, this study was conducted in the environment of neonatal intensive care, where healthcare professionals are highly educated and highly specialised. Given our representative sample of NICUs in Germany, our results are easy transferrable to other NICUs within Germany. The core message of the paper is probably also generalisable to NICUs outside Germany as the people involved-patients, parents, nurses, physicians, psychologists and son onare mostly the same in other countries. Nevertheless, the involvement of parents in the treatment process varies between European countries, ${ }^{37}$ which might limit generalisability. Outside the NICU setting, the transferability is also limited due to different circumstances and diverse professions. This leaves fruitful directions for future research in international multicentre studies.

\section{Author affiliations}

${ }^{1}$ Department of Health Economics, RWI - Leibniz Institute for Economic Research, Essen, Germany

${ }^{2}$ Ruhr-University Bochum, Bochum, Germany

${ }^{3}$ Department of Neonatology and Pediatric Intensive Care, Children's Hospital, University Hospital Cologne, Cologne, Germany

${ }^{4}$ Department of Business Administration and Healthcare Management, University of Cologne, Cologne, Germany

${ }^{5}$ Department for Nursing and Health Care, Hannover University of Applied Sciences and Arts, Hannover, Germany

${ }^{6}$ Faculty of Public Health Services, Ostfalia University of Applied Sciences - Campus Wolfsburg, Wolfsburg, Germany

Correction notice This article has been corrected since it was published. Two times a 3 instead of 6 appeared in the Results part of the abstract.

Acknowledgements We are indebted to the medical and nursing teams in participating neonatal intensive care unit (NICUs) as well as all colleagues of the Health Services Research in Neonatal Intensive Care Units research project. For their excellent cooperation, we would like to thank Professor Christiane Woopen as head of the subproject 'Ethical Aspects', Professor Rainer Riedel as head of the subproject 'Economic Outcomes' and Professor Holger Pfaff as head of the collaborating Institute of Medical Sociology, Health Services Research and Rehabilitation Science of the University of Cologne. A special thank you goes to Dr Anika Nitzsche for her helpful methodological advice. The following hospitals and investigators participated in the study: Department of Neonatology, Klinikum Frankfurt (Oder): Cornelia Ast, MD; Department of Neonatology, Children's Hospital, Marienhospital Bottrop gGmbH: Sezgin Ata, MD; Children's Hospital, St. Vincenz-Krankenhaus GmbH: Björn Beckers, MD; Department of Neonatology and Pediatric Intensive Care, University Medical Centre Greifswald: Anke Beyersdorff, MD; Department of Neonatology, Charité University Medical Centre Berlin: Christoph Bührer, MD; Children's Hospital, Klinikum Oberberg GmbH:
Salem El-Hamid, MD; Children's University Hospital, Johannes Wesling Klinikum Minden: Bernhard Erdlenbruch, MD; Department of Neonatology, GFO Kliniken Bonn: St. Marien Hospital: Werner Garbe, MD; Department of Neonatology, Dr von Hauner Kinderspital, Klinikum der Universität München: 0 Genzel-Boroviczény, MD; Department of Neonatology, Christophorus-Kliniken Coesfeld: Hubert Gerleve, MD; Department of Neonatology and Pediatric Intensive Care, Children's Hospital, Marienhospital Witten: Baham Gharavi, MD; Department of Neonatology, Children's Hospital Lübeck, University Hospital Schleswig-Holstein: Wolfgang Göpel, MD; Department of Neonatology, St. Marien- und St. Annastiftskrankenhaus: Birgit Görtz, MD; Department of Neonatology and Pediatric Intensive Care, University Hospital Halle, Martin-Luther University Halle: Roland Haase, MD; Department of Neonatology, Children's Hospital, Diakoniekrankenhaus Bad Kreuznach: Edmondo Hammond, MD; Department of Neonatology and Pediatric Intensive Care, Children's Hospital, Helios Klinikum Krefeld: Peter Heister, MD; Department of Neonatology, Children's Hospital, University of Witten/Herdecke, HELIOS University Hospital Wuppertal: Michael Heldmann, MD; Department of Neonatology and Pediatric Intensive Care, Children's Hospital, University Hospital of Freiburg: Roland Hentschel, MD; Department of Neonatology, Children's Hospital St. Marien, Landshut: Reinhard Herterich, MD; Department of Neonatology, Children's Hospital, Krankenhaus St. Elisabeth und St. Barbara Halle (Saale) GmbH: Claudia Heß, MD; Department of Neonatology and Pediatric Intensive Care, Children's Hospital, Klinikum Itzehoe: Georg Hillebrand, MD; Children's Hospital, Gesundheitszentrum Rheine, Mathias-Spital: Hans-Georg Hoffmann, MD; Children's Hospital, Evangelisches Krankenhaus Lippstadt: Thomas Hofmann, MD; Department of Neonatology, Heinrich-Heine-University Düsseldorf: Thomas Höhn, MD; Children's Hospital, Klinikum Leverkusen gGmbH: Peter Jahn, MD; Children's Hospital, Evangelisches Waldkrankenhaus Spandau, Berlin: Frank Jochum, MD; Children's Hospital, OVGU-University Magdeburg: Gerhard Jorch, MD; Department of Neonatology Ostbayern, Children's Hospital, Kliniken Dritter Orden gGmbh Passau: Matthias Keller, MD; Children's Hospital, Bethlehem Gesundheitszentrum Stolberg gGmbH: Heiner Kentrup, MD; Department of Neonatology, University of Regensburg, Klinik St. Hedwig, Krankenhaus Barmherzige Brüder: Jochen Kittel, MD; Children's Hospital, HELIOS Dr. Horst Schmidt Kliniken Wiesbaden: Markus Knuf, MD; Department of Neonatology and Pediatric Intensive Care, Children's Hospital, Klinikum Links der Weser gGmbH: Hans Thorsten Körner, MD; Department of Neonatology, Städtisches Klinikum Karlsruhe gGmbH: Alexander Krauth, MD; Department of Neonatology, Children's Hospital, University Hospital of Cologne: Angela Kribs, MD; Department of Neonatology, University Medical Centre Göttingen: Helmut Küster, MD; Department of Neonatology, Children's Hospital, DRK Kliniken Berlin Westend: Arpad von Moers, MD; Department of Neonatology and Pediatric Intensive Care, University Hospital of Bonn: Andreas Müller, MD; Children's Hospital, Klinikum Kassel: Dirk Müller, MD; Department of Neonatology, Children's Hospital, Klinikum Memmingen: Ralf Pallacks, MD; Department of Neonatology and Pediatric Intensive Care, DRK Kinderklinik Siegen: Markus Pingel, MD; Department of Neonatology, Children's Hospital, Klinikum Fulda: Reinald Repp, MD; Children's Hospital, Vivantes Klinikum Neukölln: Rainer Rossi, MD; Department of Neonatology, Children's Hospital, Katholisches Karl-Leisner-Klinikum gGmbH, St.-Antonius-Hospital, Kleve: Jochen Rübo, MD; Children's University Hospital, Paracelsius Medizinische Privatuniversität, Klinikum Nürnberg Süd: Stefan Schäfer, MD; Children's Hospital, St. Joseph-KH Berlin: Antje Schlesinger, MD; Department of Neonatology, Children's Hospital, University Hospital of Frankfurt: Rolf L. Schlößer, MD; Children's Hospital, Städtisches Klinikum Dresden/Neustadt: Stefan Schmidt, MD; Department of Neonatology, Children's Hospital, Klinikum Esslingen GmbH: Christian von Schnakenburg, MD; Department of Neonatology Nordostbayern, St. Marien, Amberg: Alexander Schnelke, MD; Children's Hospital, Stauferklinikum Schwäbisch Gmünd: Birgit Schwander, MD; Department of Neonatology and Pediatric Intensive Care, Children's Hospital, Klinikum Worms gGmbH: Heino Skopnik, MD; Children's Hospital, Harzklinikum Dorothea Christiane Erxleben: Dieter Sontheimer, MD; Department of Neonatology, Children's Hospital, Klinikum Herford: Uwe Spille, MD; Children's Hospital, Klinikum Mutterhaus der Borromäerinnen: Wolfgang Thomas, MD; Children's Hospital, University of Erlangen-Nürnberg: Hans Georg Topf, MD; Department of Neonatology, Children's Hospital, Klinikum Singen: Andreas Trotter, MD; Department of Neonatology and Pediatric Intensive Care Medicine, Asklepios Klinik Sankt Augustin: Beatrix Wiebe, MD; Department of Neonatology and Pediatric Intensive Care Medicine, Klinikum Aschaffenburg: Christian Wieg, MD; Children's Hospital, Caritas Hospital Bad Mergentheim: Christian Willaschek, MD; Department of Neonatology, DONAUISAR Klinikum Deggendorf: Michael Welsch, MD; Department of Neonatology and Pediatric Intensive Care, Altonaer Kinderkrankenhaus gGmbH: Axel von der Wense, MD; Department of Neonatology, Children's Hospital, Carl-Thiem-Klinikum Cottbus gGmbH: Ulrike Wetzel, MD; Department of Neonatology, Main-Kinzig-Kliniken: Manuel Wilhelm, MD; Department of Neonatology, Children's Hospital Bamberg: 
Alfons Wolf, MD; and Department of General Pediatrics and Neonatology, University Hospital Saarland: Caroline Wollny.

Contributors AM conceptualised and drafted the initial manuscript and performed the data analysis, in conjunction with FM and MW. VG rolled out the pilot study. FM, MW, LK, BR and VG edited the manuscript and critically reviewed its intellectual content. All authors approved the final version of the manuscript.

Funding The study was funded by the German Federal Ministry of Education and Research (grant number: 01GY1152). The publication of this article was funded by the Open Access Fund of the Leibniz Association.

Competing interests None declared.

Patient consent for publication Not required.

Ethics approval The pilot study was approved by the Ethics Committee of the University of Cologne and all other Ethic Committees of participating NICUs. The main study was approved by the Ethics Commission of the Faculty of Medicine of Cologne University (\#12-228) and staff councils of participating NICUs.

Provenance and peer review Not commissioned; externally peer reviewed.

Data availability statement The datasets generated and analysed during the current study are not publicly available for data protection reasons. According to the obligation of confidentiality statement of the study protocol, which was approved by the institutional review board, employees of the research group committed themselves to confidential handling of collected data. Data are therefore only available from the authors on reasonable request and with the written permission of the institutions taking part in the project.

Supplemental material This content has been supplied by the author(s). It has not been vetted by BMJ Publishing Group Limited (BMJ) and may not have been peer-reviewed. Any opinions or recommendations discussed are solely those of the author(s) and are not endorsed by BMJ. BMJ disclaims all liability and responsibility arising from any reliance placed on the content. Where the content includes any translated material, BMJ does not warrant the accuracy and reliability of the translations (including but not limited to local regulations, clinical guidelines, terminology, drug names and drug dosages), and is not responsible for any error and/or omissions arising from translation and adaptation or otherwise.

Open access This is an open access article distributed in accordance with the Creative Commons Attribution Non Commercial (CC BY-NC 4.0) license, which permits others to distribute, remix, adapt, build upon this work non-commercially, and license their derivative works on different terms, provided the original work is properly cited, appropriate credit is given, any changes made indicated, and the use is non-commercial. See: http://creativecommons.org/licenses/by-nc/4.0/.

ORCID iD

Anne Mensen http://orcid.org/0000-0002-6354-4369

\section{REFERENCES}

1 Thomas EJ, Williams AL, Reichman EF, et al. Team training in the neonatal resuscitation program for interns: teamwork and quality of resuscitations. Pediatrics 2010;125:539-46.

2 Thomas EJ, Sexton JB, Lasky RE, et al. Teamwork and quality during neonatal care in the delivery room. J Perinatol 2006;26:163-9.

3 Reader TW, Flin R, Mearns K, et al. Developing a team performance framework for the intensive care unit. Crit Care Med 2009;37:1787-93.

4 Suresh G, Horbar JD, Plsek P, et al. Voluntary anonymous reporting of medical errors for neonatal intensive care. Pediatrics 2004;113:1609-18.

5 Dietz AS, Pronovost PJ, Mendez-Tellez PA, et al. A systematic review of teamwork in the intensive care unit: what do we know about teamwork, team tasks, and improvement strategies? J Crit Care 2014;29:908-14.

6 Agarwal S, Frankel L, Tourner S, et al. Improving communication in a pediatric intensive care unit using daily patient goal sheets. $J$ Crit Care 2008;23:227-35

7 Narasimhan M, Eisen LA, Mahoney CD, et al. Improving nursephysician communication and satisfaction in the intensive care unit with a daily goals worksheet. Am J Crit Care 2006;15:217-22.

8 Locke EA, Latham GP. Building a practically useful theory of goal setting and task motivation. A 35-year odyssey. Am Psychol 2002;57:705-17.
9 Locke EA, Latham GP. A theory of goal setting \& task performance. Englewood Cliffs, NJ: Prentice-Hall, 1990.

10 Locke EA, Latham GP. The development of goal setting theory: a half century retrospective. Motiv Sci 2019;5:93-105.

11 Locke EA, Latham GP. Building a theory by induction: the example of goal setting theory. Organiz Psychol Rev 2020;10:223-39.

12 Gilmartin MJ, Freeman RE. Business ethics and health care: a stakeholder perspective. Health Care Manage Rev 2002;27:52-65.

13 Raelin JA. The clash of cultures: managers and professionals. Boston, MA: Harvard Business School Press, 1986.

14 Scott WR. Reactions to supervision in a heteronomous professional organization. Adm Sci Q 1965;10:65-81.

15 Wallace JE. Organizational and professional commitment in professional and nonprofessional organizations. Adm Sci Q 1995;40:228-55.

16 Hellriegel D, Slocum JW. Organizational behavior. 11th edn. Cincinatti, OH: Thomson/South-Western, 2007.

17 Sample JA. Nominal group technique: an alternative to brainstorming. J of Ext 1984;22.

18 Thommen JP. Management und Organisation: Konzepte, Instrumente, Umsetzung. Zürich: Versus Verlag, 2002.

19 Kaiser HF. The application of electronic computers to factor analysis. Educ Psychol Meas 1960;20:141-51.

20 Pick V. Der Einfluss von personal, organisation und Zusammenarbeit auf die Leistungsfähigkeit von Intensivstationen - Ergebnisse einer interdisziplinären studie Im Bereich Der Neonatologie (dissertation). Cologne, Germany: University of Cologne, 2012.

21 Nitzsche A, Kuntz L, Miedaner F. Staff working in hospital units with greater social capital experience less work-home conflict: secondary analysis of a cross-sectional study. Int J Nurs Stud 2017;75:139-46.

22 Miedaner F, Kuntz L, Enke C, et al. Exploring the differential impact of individual and organizational factors on organizational commitment of physicians and nurses. BMC Health Serv Res 2018;18:180.

23 Miedaner F, Langhammer K, Enke C, et al. Volume, size, professionals' specialization and nutrition management of NICUs and their association with treatment quality in VLBW infants. J Perinato 2018;38:402-10.

24 Cronbach LJ. Coefficient alpha and the internal structure of tests. Psychometrika 1951;16:297-334

25 Schumacker RE, Lomax RG. A beginner's guide to structural equation modeling. 2nd edn. Mahwah, NJ: Lawrence Erlbaum Associates, 2004.

$26 \mathrm{Hu}$ Li-tze, Bentler PM. Cutoff criteria for fit indexes in covariance structure analysis: conventional criteria versus new alternatives. Struct Equat Model: Multidis J 1999;6:1-55.

$27 \mathrm{Ng}$ GWY, Pun JKH, So EHK, et al. Speak-up culture in an intensive care unit in Hong Kong: a cross-sectional survey exploring the communication openness perceptions of Chinese doctors and nurses. BMJ Open 2017;7:e015721.

28 Senot C, Chandrasekaran A, Ward PT. Collaboration between service professionals during the delivery of health care: evidence from a multiple-case study in U.S. hospitals. J Operat Manag 2016;4243:62-79.

29 Latour JM. Hazelzet jam Duivoorden HJ, van Goudoever JB. perceptions of parents, nurses and physicians on neonatal intensive care practices. J Pediatr 2010;157:215-20.

30 Locke EA, Smith KG, Erez M, et al. The effects of intra-individual goal conflict on performance. J Manage 1994;20:67-91.

31 Seijts GH, Latham GP. The effects of goal setting and group size on performance in a social dilemma. Can J Behav Sci 2000;32:104-16.

32 Kowalski WJ, Leef KH, Mackley A, et al. Communicating with parents of premature infants: who is the informant? J Perinatol 2006;26:44-8.

33 Pick V, Halstenberg K, Demel A, et al. Staff and parents are discriminators for outcomes in neonatal intensive care units. Acta Paediatr 2014;103:e475-83.

34 Franck LS, Axelin A. Differences in parents', nurses' and physicians' views of NICU parent support. Acta Paediatr 2013;102:590-6.

35 Scheffler RM, Liu JX, Kinfu Y, et al. Forecasting the global shortage of physicians: an economic- and needs-based approach. Bull World Health Organ 2008;86:516-23.

36 Liu JX, Goryakin Y, Maeda A, et al. Global health workforce labor market projections for 2030. Hum Resour Health 2017;15.

37 Cuttini M, Croci I, Toome L, et al. Breastfeeding outcomes in European NICUs: impact of parental visiting policies. Arch Dis Child Fetal Neonatal Ed 2019;104:F151-8. 